\title{
The Change of Electrical Resistivity Accourding to Different Quench Techniques in Copper-Manganese Alloy
}

\author{
E. Aldırmaz* \\ Department of Physics, Amasya University, Amasya, Turkey. \\ M. Guler \\ Department of Physics, Hitit University, Corum, Turkey. \\ E. Guler \\ Department of Physics, Hitit University, Corum, Turkey.
}

\begin{abstract}
M. Kara
Department of Mechanical Engineering, Faculty of Technology, Amasya University, Amasya, Turkey.

Article history

Received:

20.05.2016

Received in revised form: 28.06.2016

Accepted:

29.06.2016

Key words:

Electrical resistivity, $\mathrm{Cu}-\mathrm{Mn}$ alloys, Quench Rate, Fourpoint probe D.C. method.

It is known that copper has electrical and thermal conductivity. Therefore $\mathrm{Cu}$-based alloys are used in technological and engineering applications. This paper is aimed at studying influence of various heat treatment on electrical resistivity properties of samples from binary $\mathrm{Cu}-\mathrm{Mn}$ alloy. The chemical composition of the alloy was found to be $\mathrm{Cu}_{75.8}-\mathrm{Mn}_{24.2}$ (wt.\%) by using energy dispersive $\mathrm{x}$-ray analysis (EDAX) technique. Electrical resistivity is a fundamental property of many materials. Hence, it is a key physical property of all materials. The electrical properties of binary $\mathrm{Cu}-\mathrm{Mn}$ system performed by using a standard four-point probe D.C. method A Keithley 2400 sourcemeter. The resistivity measurements are carried out in the temperature range from 50 to $300{ }^{\circ} \mathrm{C}$ during heating. In the measurements, important properties were observed. The values of electrical resistivity of alloy was determined as a function of temperature. The specific resistivity changed linearly with the temperature. The differents showed the resistivity as a function of quenching temperature. The relative values of electrical resistivity also increased with increasing rate of quenching.
\end{abstract}

\footnotetext{
*Correspondence: ealdirmaz@gmail.com
} 


\section{Introduction}

Most copper-based shape memory alloys are easier to produce and process and are also inexpensive compared to $\mathrm{Ni}-\mathrm{Ti}$ shape memory alloys [1]. $\mathrm{Cu}$ and $\mathrm{Mn}$ are two important elements in several commercial alloys. Manganese is considered to be one of the most important alloying elements in different grades of steel, cast iron and copper-based alloys. Manganese improves the tensile strength, machinability, toughness, hardness, and abrasion resistance of steel [2]. The validation of regressions formulations was found to be in a good agreement with the experimental data which indicates the efficiency of the factorial design to predict the metallurgical properties of manganese ores under the influence of different impurities [3]. Much work has already done on $\mathrm{Cu}-\mathrm{Mn}$ alloys, partly because of great technical interest in the mechanical, electrical and magnetic properties of this alloy system [4]. Therefore, it is interesting to investigate the phsical properties of the $\mathrm{Cu}-\mathrm{Mn}$ alloys. Copper-based shape memory alloys are very sensitive to the thermal effects before and after the transformation. These effects may cause important changes on crystallographic properties or the other transformation parameters of the alloys [5]. Due to exposed physical and mechanical effects, metal and alloys exhibit a very surprising properties. Under the various mechanical and thermodynamic conditions, microstructural changes. The previous studies showed that the resistivity of engineering materials such as metals and alloys depend on the temperature to which the material is exposed. The purpose of this study is to determine the influences of heat treatment on electrical resistivity of $\mathrm{Cu}-\mathrm{Mn}$ alloy.

\section{Experimental}

The chemical compositions of alloy was determined as $\mathrm{Cu}_{75.8}-\mathrm{Mn}_{24.2}$ by EDX analysis. The $\mathrm{Cu}_{75.8}-\mathrm{Mn}_{24.2}$ alloy was prepared in an arc furnace under argon atmosphere using a high purity $\mathrm{Cu}$ and $\mathrm{Mn}$
(99.9 \%) powders. In this study, two heat treatments were used. First group of samples obtained from alloy was homogenized at 900 ${ }^{\circ} \mathrm{C}$ for $30 \mathrm{~min}$. in an $\mathrm{Ar}$ atmosphere and cooled to $25^{\circ} \mathrm{C}$ inside the furnace, and then air-cooled (sample 1). Other group of samples was austenitized at $900{ }^{\circ} \mathrm{C}$ for 30 min. followed by quenching in iced-water (sample 2). Measurements of electrical resistivity were made in the range of 50-300 ${ }^{\circ} \mathrm{C}$ at room temperature at the frequency of 1 $\mathrm{Hz}$ with typical 250 micrometer in diameter probe using a standard four-point probe D.C. method. A Keithley 2400 sourcemeter was used.

\section{Results and discussion}

Since we know importance of electrical properties in $\mathrm{Cu}$-based alloys, electrical resistivity of measurements have been applied to in order to search the effect of heat treatments on the electrical resistivity at room temperature. The two most common methods of measuring the transformation temperatures are by electrical resistivity and differential scanning calorimetry (DSC) measurements. Cooling process in alloy can produce permanent changes such as internal hard, dislocation and state of equilibrium deposition. The presence of vacancies play important roles to cooling $\mathrm{Cu}$-based. When cooling rate increases, also density of defects increases and lattice structure changes. Especially alloys are cooled fast at high temperature; enough time will not be for the formation of equilibrium [6-8]. This increases the concentration of vacancies and grain size influences of physical properties such as electrical resistance and electrical resistivity [9]. In our previous works, details about microstructures of alloy have been given. These studies have showed that sample consist of austenite structure with $\alpha$ precipitation which is copper-rich solid solition $[10,11]$. The resistivity measurements are carried out in the temperature range from 50 to $300{ }^{\circ} \mathrm{C}$ during heating. The heating rate is $5{ }^{\circ} \mathrm{C} / \mathrm{min}$. The values of electrical resistivity with 
temperature are performed as shown in Fig. 1.

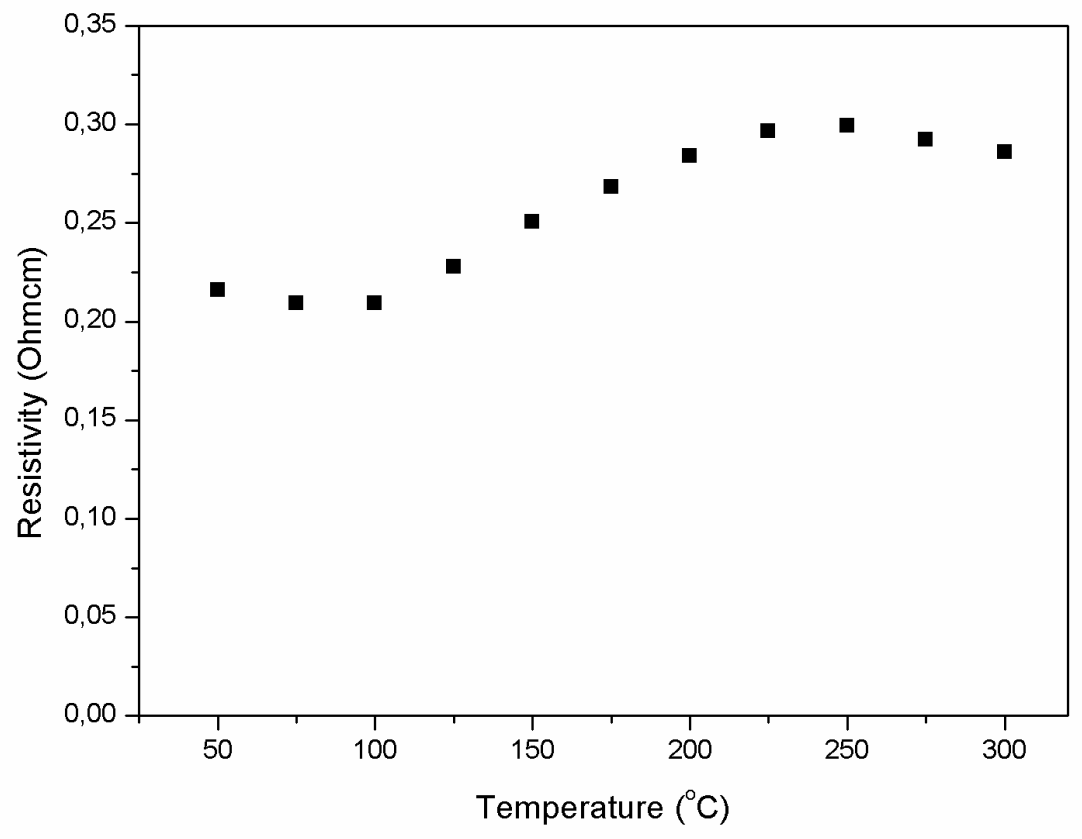

(a)

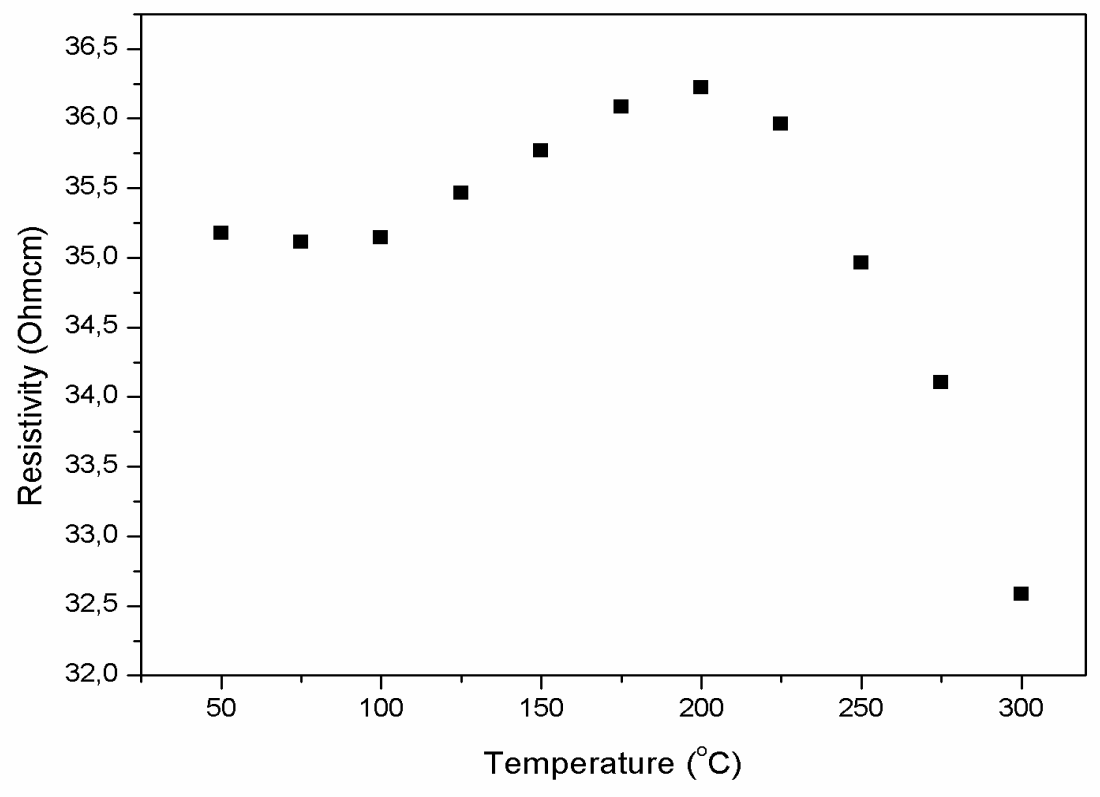

(b)

Figure 1. Electrical Resistivity as a function of temperature for samples (a) sample 1 and (b) sample 2.

$\left(100-250{ }^{\circ} \mathrm{C}\right)$ leads to an increase in In the Fig 1a shows the resistivity increases with the increasing temperature. Figure $1 \mathrm{a}$ is electrical resistivity. Figure $1 b$ is revealed observed that the increase in temperature that the resistivity is minimum at high temperatures. That is to say, phonons will 
prevail in spite of many neglecting mechanisms like electron-electron scattering, residual resistivity, and traces of magnetic impurities. The value of electrical resistivity is also affected by grain size but to a smaller extent compared to the effect of temperature and chemical composition $[12,13]$. An other result the electrical resistivity of sample 1 is increasing (after $200{ }^{\circ} \mathrm{C}$ ), in sample 2 decreased. But the electrical resistivity the sample 2 is higher than the sample 1 . It can be explaned by the combination of the uniform distribution of fine precipitation and heat treatments. The electrical resistivity strongly depends on temperature and defects. This the crystall of defects such as dislocations, vacancies, internal defects and impurity atoms. Many research reports have indicated the preferential precipitation of $\mathrm{Cu}$ rich precipitates at the open volume defects in many alloy systems. These defects act as heterogeneous nucleation sites for the formation of $\mathrm{Cu}$-rich precipitates [14-16]. The electrical resistivity is increased by small grain size and vacancies in sample 2 [9]. Amorphous magnetic alloys exhibit high electrical resistivities due to electron scattering from the atomic disorder. High resistivity results in reduced eddy currents [16].

\section{Conclusion}

In many applications, the electrical behaviour of a material is important. To select and use materials for electrical and electronic applications, we must understand how properties such as electrical conductivity are controlled. We must also realise that electrical behaviour is influenced by the structure of a material, the processing of a material, and the environment to which a material is exposed. The microstructures and electrical resistivity were investigated in the $\mathrm{Cu}-\mathrm{Mn}$ (wt.\%) alloy. When the temperature of a metal increases, thermal energy causes the atoms to vibrate. The atom may not be in its equilibrium position, and it therefore interacts with and scatters electrons. The main free path decreases, the mobility of electrons is reduced, and the resistivity increases. The $\mathrm{Cu}_{75.8}-\mathrm{Mn}_{24.2}$ alloy can be used in technological application where low or high electrical resistivity. This is particularly true in the development of new electronic materials for a variety of important technological application.

\section{References}

[1]. Amini R, Mousavizad SM, Abdollahpour $\mathrm{H}$, Ghaffari $\mathrm{M}$, Alizadeh M, Okyay AK. Structural and microstructural phase evolution during mechano-synthesis of nanocrystalline/amorphous $\mathrm{CuAlMn}$ alloy powders, Adv Powder Technol 2013; 24 :1048-1053.

[2]. Ahmed A, Ghali SN, Eissa M, El Badry SA. Influence of partial replacement of nickel by nitrogen on microstructure and mechanical properties of austenitic stainless steel. J Metall 2011;1-6.

[3]. He C, Du Y, Chen HL, Liu S, Xu H, Quyang Y, Liu ZK. Thermodynamic modeling of the $\mathrm{Cu}-\mathrm{Mn}$ system supported by key experiments. J Alloys Comp 457;2008:233-238.

[4]. Gleiter H. Nanocrystlline Materials. Prog Mater Sci 33;1989:223-315.

[5].5. Balo ŞN, Ceylan M, Aksoy M. Effects of deformation on the microstructure of a Cu- $\mathrm{Al}-\mathrm{Be}$ shape memory alloy. Mater Sci \&Eng A 2001;311:151-156.

[6].Porter DA, Easterling KE. Phase Transformations in Metals. Pergamon Pres, London: 1989.

[7]. Manosa L, Jurada M, Alfons GC, Obrado E, Planes A, Zarestky J, Stassis C, Romero R, Somazo A, Morin M. A comparative study of the post-quench behaviour of $\mathrm{Cu}-\mathrm{Al}-\mathrm{Be}$ and $\mathrm{Cu}-\mathrm{Zn}-\mathrm{Al}$ shape memory alloys. Acta Mater 1998;46:1045-1053.

[8]. Kayalı N, Zengin R, Adiguzel O Influence of Aging on Transformation Characteristics in 
Shape Memory CuZnAl Alloys. Metall Mater Transac A 2000;31:349354.

[9]. Kostrubiec B, Wiśniewski R, Rasek J. Influence of point defects and grains size on the course of reversible martensite transformation in melt spun ribbons of the copper based alloys. J Achievements in Mater. Manufac Eng 2006;16:30-34.

[10]. Aldırmaz E, Celik H, Tekelioglu A, Aksoy I. Effects of thermal treatments on mechanical properties of $\mathrm{Cu}-24.2 \% \mathrm{Mn}$ alloy. J Optoelect Adv Mater 2012;14:809-813.

[11]. Karakaya N, Aldirmaz E. Research on change of phase transformation temperatures and electrical resistance triggered by heat treatment of alloy from $\mathrm{Cu}-\mathrm{Mn}$ system. Appl. Phys. A 2016;122:542-547.

[12]. Rudnev V, Loveless D, Cook R, Black M. Handbook of Induction Heating, Markel Dekker Inc., USA. 2003.

[13]. Koikea J, Wada M. Self forming diffusion barier layer in $\mathrm{Cu}-\mathrm{Mn}$ alloy. App. Phys. Letters 2005;87, 04191113

[14].He SM, Dijk NHV, Schut H, Peekstok ER, Zwaag SV. Thermally activated precipitation at deformation-induced defects in $\mathrm{Fe}-\mathrm{Cu}$ and $\mathrm{Fe}-\mathrm{Cu}-\mathrm{B}-\mathrm{N}$ alloys studied by positron annihilation spectroscopy. Phy Rev B 2010;81:094103.

[15].Negm SE Influence of silver additions on electrical, mechanical and structures properties of rapidly solidified $\mathrm{Sn}-0.7 \% \mathrm{Cu}$ alloy from melt. J Mater Sci Mater Electronics 2012;23:94-99.

[16]. Mahmud S MD. Study of Structural and Magnetic Characteristics of $\mathrm{Cr}$ Substituted Fe-Based Nanocrystalline Alloys, Ph. D. Thesis, APRIL-2008. 